\title{
Aquiclude Stability Evaluation and Significance Analysis of Influencing Factors of Close-Distance Coal Seams: A Case Study of the Yili No. 4 Coal Mine in Xinjiang, China
}

\author{
Shuaishuai Liang, ${ }^{1,2}$ Dongsheng Zhang, ${ }^{1,2}$ Gangwei Fan $\mathbb{D D}^{1,2}$ Wenhao Guo, ${ }^{1,2}$ \\ Shouyang Gao, ${ }^{1,2}$ Shuai Zhang, ${ }^{1,2}$ Zhanglei Fan, ${ }^{1,2}$ and Wei Yu ${ }^{1,2}$ \\ ${ }^{1}$ School of Mines, China University of Mining \& Technology, Xuzhou, Jiangsu 221116, China \\ ${ }^{2}$ State Key Laboratory of Coal Resources and Safe Mining, China University of Mining \& Technology, Xuzhou, \\ Jiangsu 221116, China \\ Correspondence should be addressed to Gangwei Fan; fangw@cumt.edu.cn
}

Received 1 August 2021; Accepted 5 October 2021; Published 25 October 2021

Academic Editor: Yuanyuan Zha

Copyright (c) 2021 Shuaishuai Liang et al. This is an open access article distributed under the Creative Commons Attribution License, which permits unrestricted use, distribution, and reproduction in any medium, provided the original work is properly cited.

\begin{abstract}
Aquiclude stability is vital for the realization of water-preserving coal mining. And its evaluation, influencing factors, and their significance analysis are quite topical for the ecosystem conservation. The purpose of this paper was to establish an evaluation index system of weakly cemented aquiclude stability. An evaluation index system was built based on three evaluation factors (subsidence, seepage, and deformation), three subfactors (subsidence gradient, seepage rate, and horizontal deformation), and four evaluation criteria (unstable, weakly stable, medium stable, and stable). The evaluation method was applied to evaluate the index for the case study of Yili No. 4 Coal Mine in Xinjiang, China. Based on the geological conditions of the close-distance coal seams in the mine under study, the main influencing factors and subordinate functions of evaluation index Sta were analyzed. The above three factors' weights were assessed as 0.1095, 0.3090, and 0.5815, respectively, and the proposed evaluation method's feasibility was verified by the water level variation in the observation hole. The range and variance analyses were performed to assess the significance of the mining heights of the upper and lower coal seams and the coal seam spacing. The results showed that the aquiclude stability negatively correlated with the mining heights and positively correlated with the coal seam spacing. The decreasing order of influence significance on the aquiclude stability was as follows: upper coal seam mining height, lower coal seam mining height, and coal seam spacing. Water protection mining was an effective measure to control the Sta, and the findings provided a reference value and academic significance for the ecosystem conservation.
\end{abstract}

\section{Introduction}

Mining of shallow coal seams in areas with scarce water resources and environmental problems inevitably causes the overlying rock subsidence and groundwater level drop, jeopardizing the fragile ecological balance [1-3]. In particular, this refers to the arid and semiarid regions of western China, for which the water-preserving mining seems to be the most lucrative solution [4-7]. Water-preserving mining is concerned with the protection of water resources throughout the process of mining. This is critical for rationally realizing green and climate-smart mining [8]. Its realization depends, in turn, on the aquiclude stability control and its robust substantiation. Therefore, the quantitative evaluation of aquiclude stability has important guiding significance for water-preserving mining [9-12].

The impact of coal seam mining on shallow water resources can be reduced to the following three cases: (1) The aquifer water level remains unchanged. (2) The aquifer water level decreases. (3) The aquifer water level restores after decreasing. Numerous experts and scholars have studied the aquifer water level behavior using different test methods and criteria. Thus, several authors reported that the relationship between the development height of the 
fracture zone controlled by the key stratum and the waterresisting key strata and the aquifer determined the variation behavior of the aquifer's water level [13-17]. When the aquifer is above the fracture zone, the water level does not change; otherwise, the water level drops. Alternatively, other researchers reported that the degree of development of cracks in aquicludes determines the variation behavior of the aquifer level [18-20]. When the upward and downward cracks penetrate through the aquiclude, the water level drops; otherwise, the water level does not change. Other researchers studied the tensile, shear, and bending failure criteria of aquiclude stability through laboratory experiments and theoretical analysis [21-23]. Other researchers explored the water level changes before and after mining through on-site observation of the aquifer water level [24-26]. It was found that the water level gradually recovered after the drop. The above findings were mainly related to cases where the fracture zone reached the aquiclude or the aquiclude deformation reached its limiting value. They provided no quantitative assessment of the aquiclude stability or considered the seepage effect. In coal-bearing strata of western China, which have a short diagenesis time, aquicludes are rich in clay minerals, such as montmorillonite, illite, and kaolin, and are prone to swelling and sealing fractures when exposed to water $[27,28]$. As a result, such aquicludes are not necessarily completely destabilized after cracks are generated, or the deformation reaches the limit value. Therefore, the stability assessment of such aquicludes from the aspects of fracture development and deformation does not conform to the real situation. Therefore, it is necessary to develop a new aquiclude stability assessment method.

The aquiclude stability is mainly affected by geological factors (topography, geological structure, hydrogeology, stratum lithology, etc.) and mining factors (mining height, mining speed, working face size, working face layout, etc.) $[29,30]$. Among them, geological factors are the unchangeable and artificial uncontrollable factors formed during geological tectonic movement. In contrast, mining factors are artificially controllable factors that have a significant effect on aquiclude stability. Multiple researchers have studied the effect of different factors on aquiclude stability for close-distance coal seams mining. Thus, some authors explored the development of water-flowing fracture zone under the conditions of close-distance coal seams through physical simulation and field measurement and analyzed the feasibility of close-distance coal seams mining with water preservation $[31,32]$. Other authors investigated the influence of different stratum structures of coal seams on the development of overlying stratum cracks and classified the close-distance coal seams into three types: no inferior key stratum between coal seams, single inferior key stratum between coal seams, and two or more inferior key strata between coal seams $[33,34]$. Other authors studied the influence of mining staggered distance of the upper and lower coal seam on aquiclude stability through physical analog model and numerical simulation, as well as substantiated the optimal mining staggered distance [35]. Other authors investigated the effect of bedrock thickness and coal seam spacing on the aquiclude stability [36, 37]. They reported that with the bedrock thickness increase, the development degree of water-flowing fracture zone decreased, improving the aquiclude stability. With an increase in the interlayer spacing, the development degree of secondary cracks dropped, and the aquiclude stability improved. In summary, previous studies provided a single-factor analysis of multiple factors on aquiclude stability, without their ranking or interaction account. Therefore, it is necessary to comprehensively consider various influencing factors and study their significance to substantiate the optimal water-preserving mining conditions in close-distance coal seams.

Based on the geological conditions, subsidence, seepage, and deformation perspectives of the close-distance coal seams in the Yili No. 4 Coal Mine located in the Xinjiang Uygur Autonomous Region of China, this paper established an aquiclude stability evaluation system with three evaluation factors (subsidence, seepage, and deformation), three subfactors (subsidence gradient, seepage rate, and horizontal deformation), and four evaluation criteria (unstable, weakly stable, medium stable, and stable). Besides, a multifactor analysis of aquiclude stability was carried out to determine the significance of the upper coal seam mining height, seam spacing, and the lower coal seam mining height on aquiclude stability. It provides a reference for the design of waterpreserving mining parameters for close-distance coal seams in the Yili No. 4 Coal Mine and similar ones.

\section{Methodology}

2.1. Aquiclude Stability Evaluation System and Evaluation Criteria. Aquiclude stability is the result of the joint effect of many factors, which may be coupled (interrelated). It is not rigorous to evaluate the stability of the aquiclude from singlefactor analysis. Referencing to the existing literature, it was discovered that subsidence, seepage, and deformation are the key aspects affecting the stability of aquiclude, which have not yet been comprehensively incorporated in the evaluation system. Among the three aspects, subsidence gradient of aquiclude can effectively represent the longitudinal shear action, seepage velocity can effectively represent the erosion effect on aquiclude, and horizontal deformation can effectively represent the transverse tensile action. In this paper, starting from the properties of aquiclude subsidence, seepage, and deformation, three influencing factors, namely, (i) the aquiclude subsidence gradient, (ii) seepage rate, and (iii) horizontal deformation, were selected to evaluate the stability of aquiclude comprehensively.

For the evaluation of aquiclude stability, a fuzzy comprehensive evaluation method was applied. The fuzzy comprehensive evaluation method is based on the fuzzy mathematical correlation theory. It is a mathematical model used to comprehensively evaluate the systems that evaluations are based on complexity and fuzziness. Different from the absolute membership in conventional sets, where a factor belongs to a set or not ( 0 or 1 ), the fuzzy set assesses the membership degree of a factor in the set as any number in the closed interval $[0,1]$, replacing absolutely belonging (yes or no) with relative belonging.

For the evaluation criteria, referring to the mining water barrier classification of aquicludes by $\mathrm{Yu}$ [38], the aquiclude stability was classified by the following four levels: unstable, 
TABLE 1: Evaluation indices of aquiclude stability performance.

\begin{tabular}{lcccc}
\hline Level $V$ & Unstable & Weakly stable & Medium stable & Stable \\
Evaluation index Sta & $0-0.25$ & $0.25-0.5$ & $0.5-0.75$ & $0.75-1$ \\
\hline
\end{tabular}

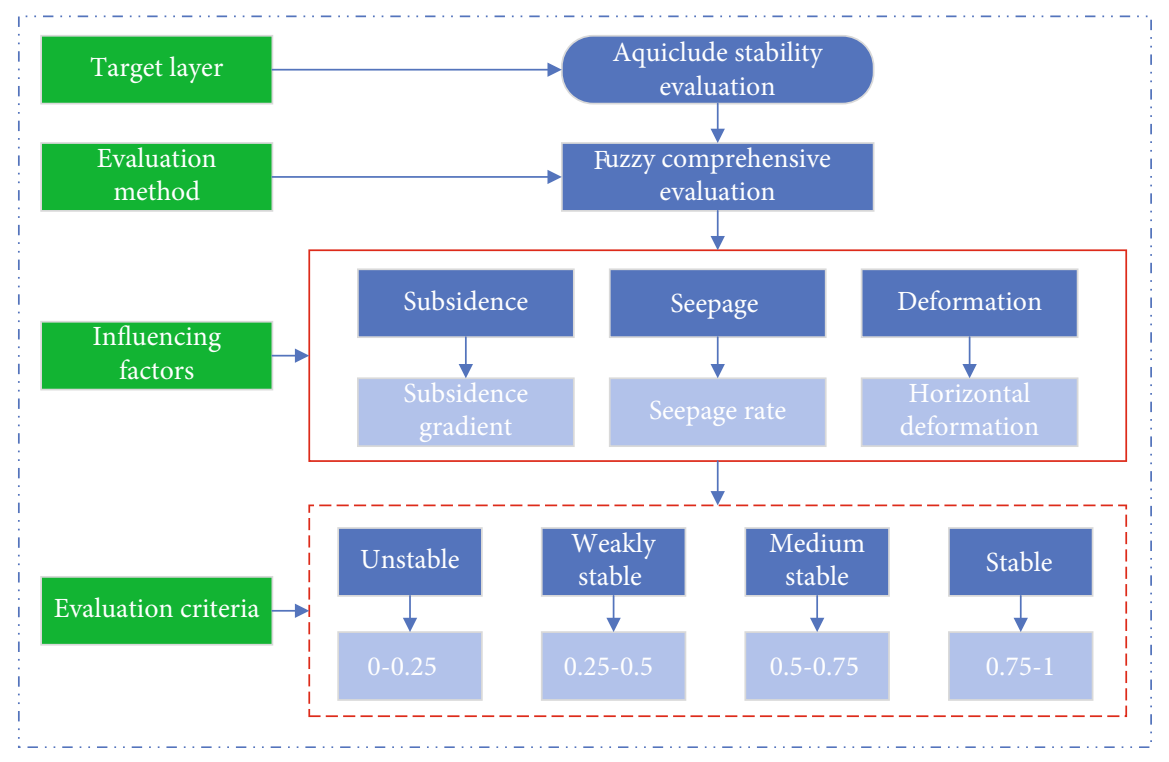

FIGURE 1: The evaluation index system.

TABle 2: Comparison judgment matrix.

\begin{tabular}{lccc}
\hline$A \sim B$ & $B_{1 \text { subsidence gradient }}$ & $B_{\text {2seepage rate }}$ & $B_{\text {3horizontal deformation }}$ \\
\hline$B_{1}$ & 1 & $1 / 3$ & $1 / 5$ \\
$B_{2}$ & 3 & 1 & $1 / 2$ \\
$B_{3}$ & 5 & 2 & 1 \\
\hline
\end{tabular}

TABLE 3: The Saaty average random consistency index.

\begin{tabular}{|c|c|c|c|c|c|c|c|c|c|}
\hline$n$ & 1 & 2 & 3 & 4 & 5 & 6 & 7 & 8 & 9 \\
\hline RI & 0 & 0 & 0.58 & 0.94 & 1.12 & 1.24 & 1.32 & 1.41 & 1.45 \\
\hline
\end{tabular}

weakly stable, medium stable, and stable. The interval from 0 to 1 was split into four equal segments to characterize the stability of aquiclude (Sta). The specific evaluation levels $V$ and evaluation values Sta are shown in Table 1.

In summary, based on the above influencing factors, evaluation method, and evaluation criteria, referring to the methods of establishing evaluation index system of other scholars [8, 39, 40], the following evaluation index system is established, as shown in Figure 1.

\subsection{Membership Function Determination}

(1) Aquiclude subsidence gradient

The subsidence gradient represents the change of subsidence per unit length. Its impact on the aquiclude is mainly manifested in the longitudinal shear effect, which produces shear cracks and affects the stability of the aquiclude structure, causing water loss. Based on the geological conditions of the Yili No. 4 Coal Mine, semitrapezoidal and trapezoidal distributions were selected to determine relevant parameters, and the subsidence gradient was determined as the membership function of the evaluation standard:

$$
\mu(i)= \begin{cases}1, & i<0.1 \\ 2-10 i, & 0.1 \leq i \leq 0.2 \\ 0, & i>0.2\end{cases}
$$

where $i\left(\mathrm{~m} \mathrm{~m}^{-1}\right)$ is the subsidence gradient.

(2) Aquiclude seepage rate

Aquiclude seepage rate has a great impact on the stability of the aquiclude. It is mainly manifested in the erosion effect on the aquiclude, which creates water channels and affects the seepage stability of the aquiclude, causing the loss of water resources. Similar to previous subsection, semitrapezoidal and trapezoidal distributions were used to determine the relevant parameters, and the membership function with the seepage rate as the evaluation standard was determined:

$$
\mu(v)= \begin{cases}1, & v<1.0 \times 10^{-8}, \\ 1.1-10^{7} v, & 1.1 \times 10^{-7} \geq v \geq 1.0 \times 10^{-8}, \\ 0, & v>1.1 \times 10^{-7}\end{cases}
$$

where $v\left(\mathrm{~m} \mathrm{~s}^{-1}\right)$ is the seepage rate. 


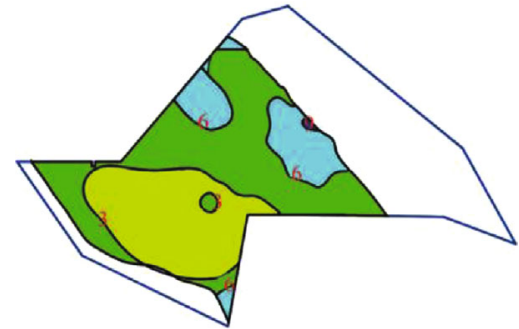

(a) Thickness of the 21-1 coal seam

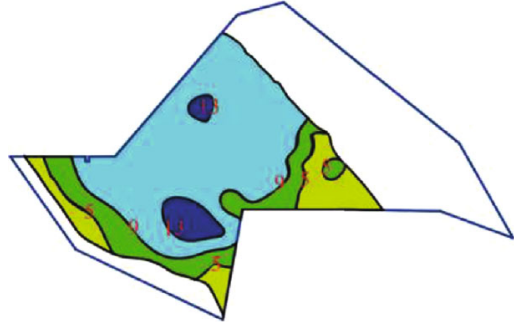

(b) Thickness of the 23-2 coal seam

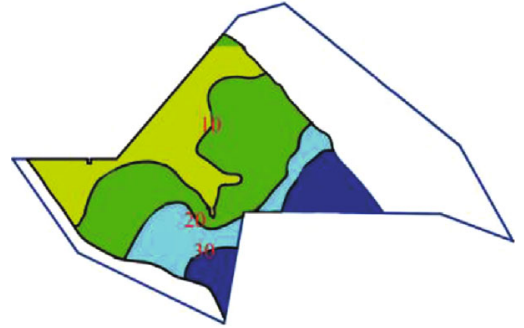

(c) Seam spacing

Figure 2: Subdivision of the coal seam structure in the mining area.

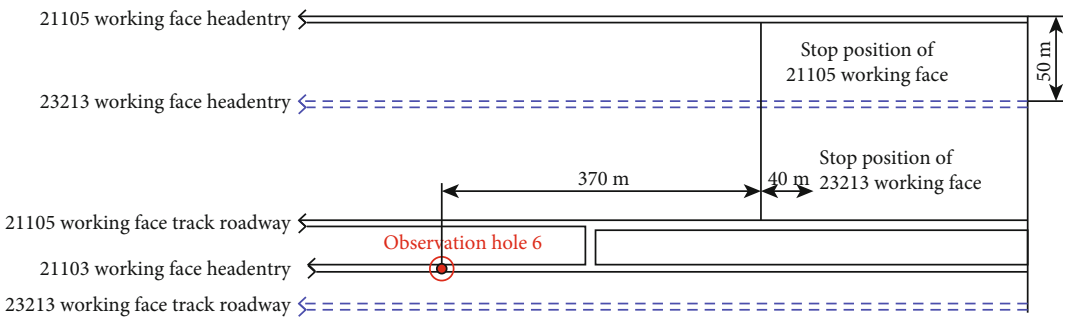

Working face layout

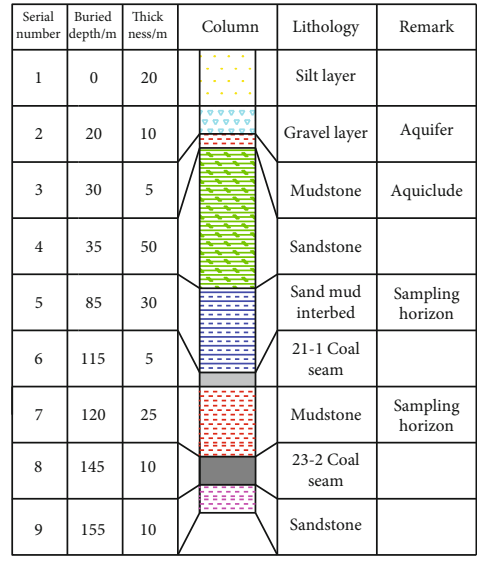

Comprehensive histogram

FIGURE 3: Working face layout and comprehensive histogram.

\section{(3) Horizontal deformation of aquiclude}

The horizontal deformation of the aquiclude has a significant impact on the stability of the aquiclude. It is mainly manifested in the lateral stretching effect on the aquiclude, resulting in tensile cracks and affecting the aquiclude structure's stability, causing water loss. For semitrapezoidal and trapezoidal distributions of relevant parameters, the membership function with the horizontal deformation as the evaluation standard was derived as follows:

$$
\mu(\varepsilon)= \begin{cases}1, & \varepsilon<0.005 \\ 1.2-40 \varepsilon, & 0.030 \geq \varepsilon \geq 0.005 \\ 0, & \varepsilon>0.030\end{cases}
$$

where $\varepsilon\left(\mathrm{m} \mathrm{m}^{-1}\right)$ is the horizontal deformation.

2.3. Weight Calculation of Impact Factors. The evaluation index system of aquiclude stability is complex and comprehensive, and different factors are interrelated. For instance, aquiclude horizontal deformation affects the width of cracks and then the seepage rate. On the contrary, the seepage rate affects the expansion characteristics of the aquiclude and then the cracks width. Therefore, how to accurately determine the weight of each factor is significant for the evaluation results. In this paper, using the " $1-9$ " scaling method, the scale value was evaluated based on the relative magnitude of the influence of each impact factor on the aquiclude stability evaluation, and the judgment matrix was established by pairwise comparison, as shown in Table 2 . Then, the weight of each influencing factor was calculated, which finally yielded the evaluation index.

The steps for obtaining the weight of each factor were as follows:

(1) Normalization of the column vector of the judgment matrix: $A_{i j}=\left(a_{i j} / \sum_{i=1}^{n} a_{i j}\right)$

(2) Matrix summation by the rows of $A_{i j}$ :

$W_{i j}=\left(\sum_{j=1}^{n} a_{1 j} / \sum_{i=1}^{n} a_{i j}, \sum_{j=1}^{n} a_{2 j} / \sum_{i=1}^{n} a_{i j}, \cdots, \sum_{j=1}^{n} a_{n j} / \sum_{i=1}^{n} a_{i j}\right)^{\mathrm{T}}$

(3) $W_{i j}$ was normalized to get the sort vector: $W=$ $\left(w_{1}, w_{2}, \cdots, w_{n}\right)^{\mathrm{T}}$

After calculation, we got the following:

$$
W_{A \sim B}\left(B_{1}, B_{2}, B_{3}\right)=(0.1095,0.3090,0.5815) .
$$




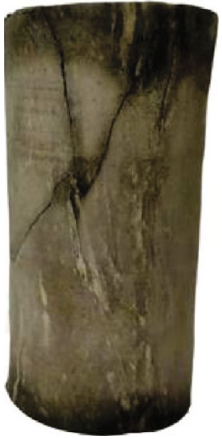

(a) Mudstone

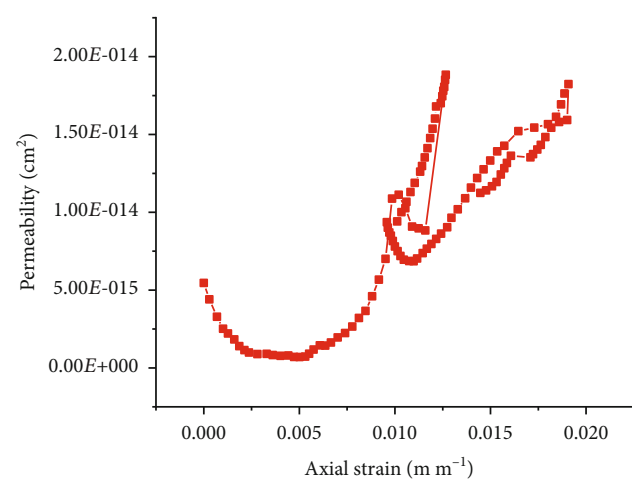

(b) Permeability-axial strain relationship
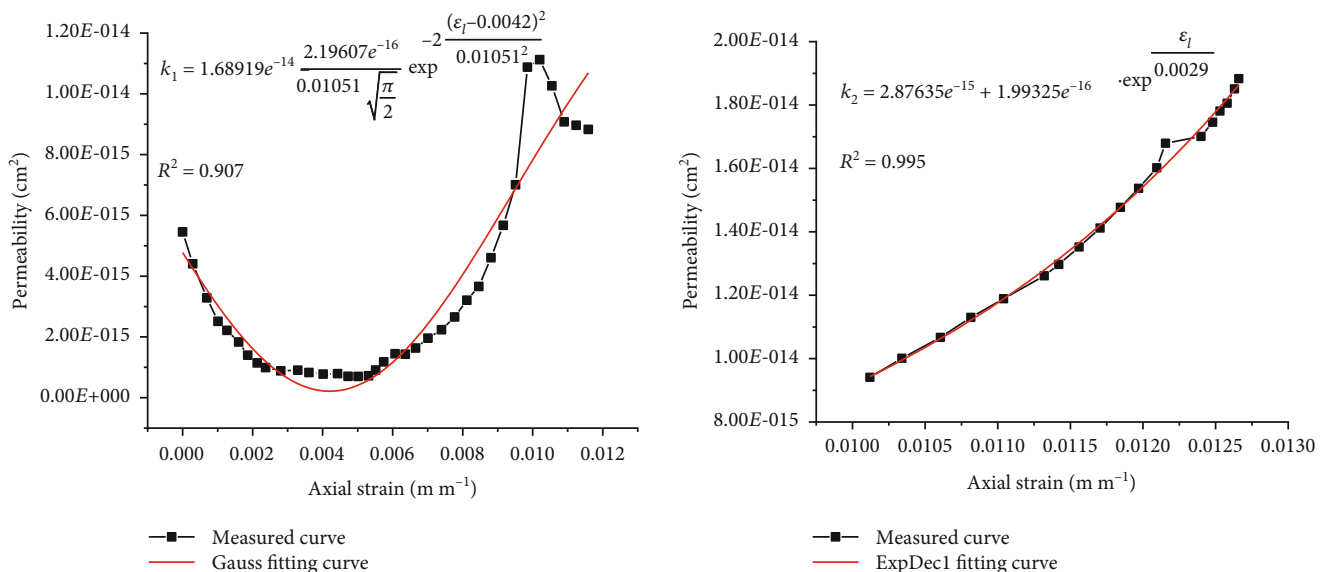

First loading stage
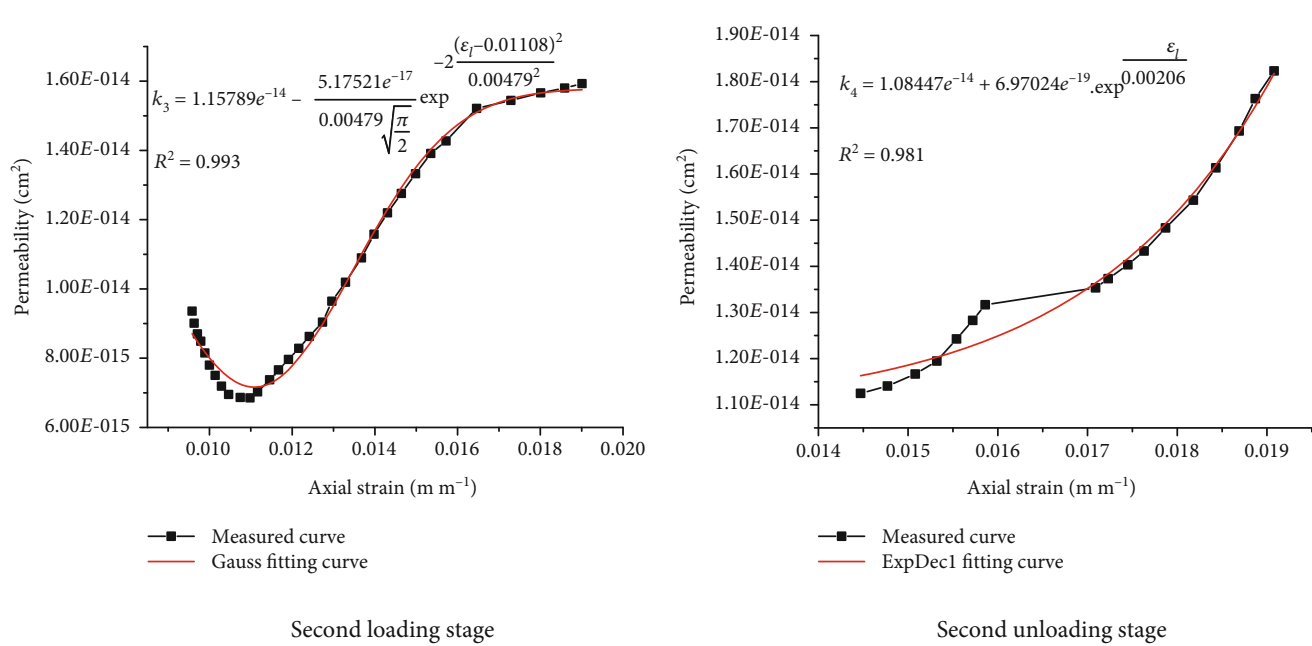

(c)

FIGURE 4: Fitting of the relationship between permeability and axial strain of mudstone at different loading and unloading stages.

Next, a consistency test on the value of $\mathrm{CR}=\mathrm{CI} / \mathrm{RI}$ was conducted, where $\mathrm{CI}=\left(\lambda_{\max }-n\right) /(n-1)$. The largest eigenvalue of the matrix was derived as $\lambda_{\max }=1 / n \sum_{i=1}^{n}$ $(\mathrm{AW})_{i} / w_{i}=3.0037$, and the value of RI was based on the Saaty average random consistency index, as shown in Table 3.

If $\mathrm{CR}<0.1$, the judgment matrix passed the consistency test; otherwise, it had to be adjusted. After calculation, we got $\mathrm{CI}=0.0019$ and the above matrix's $\mathrm{CR}=0.0033$. Since the latter was less than 0.1 , it passed the consistency test.

\section{Case Study Analysis and Verification}

3.1. Hydrogeological Conditions of the Yili No. 4 Coal Mine. The Yili No. 4 Coal Mine, owned by the Shandong Energy Xinwen Mining Group Co., Ltd., is located in Huocheng County, Yili Prefecture, Xinjiang Uygur Autonomous Region of China. It was put into operation in the fourth quarter of 2018, with the designed production capacity of 6 million tons per year. 


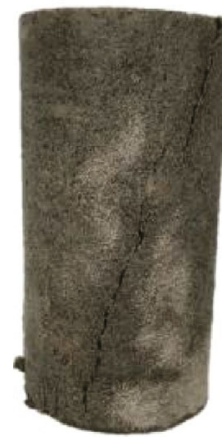

(a) Sandstone

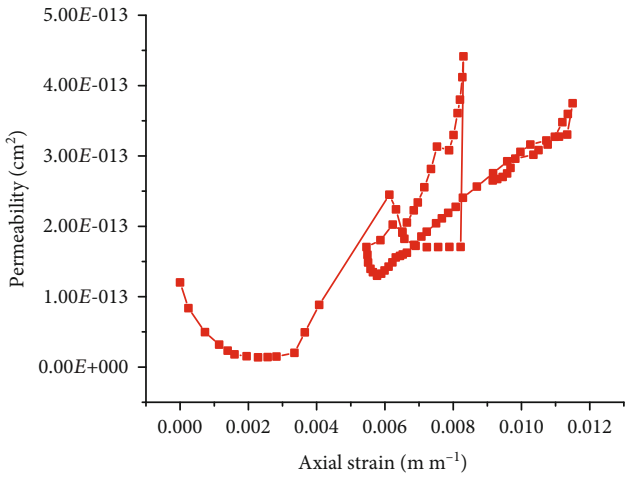

(b) Permeability-axial strain relationship
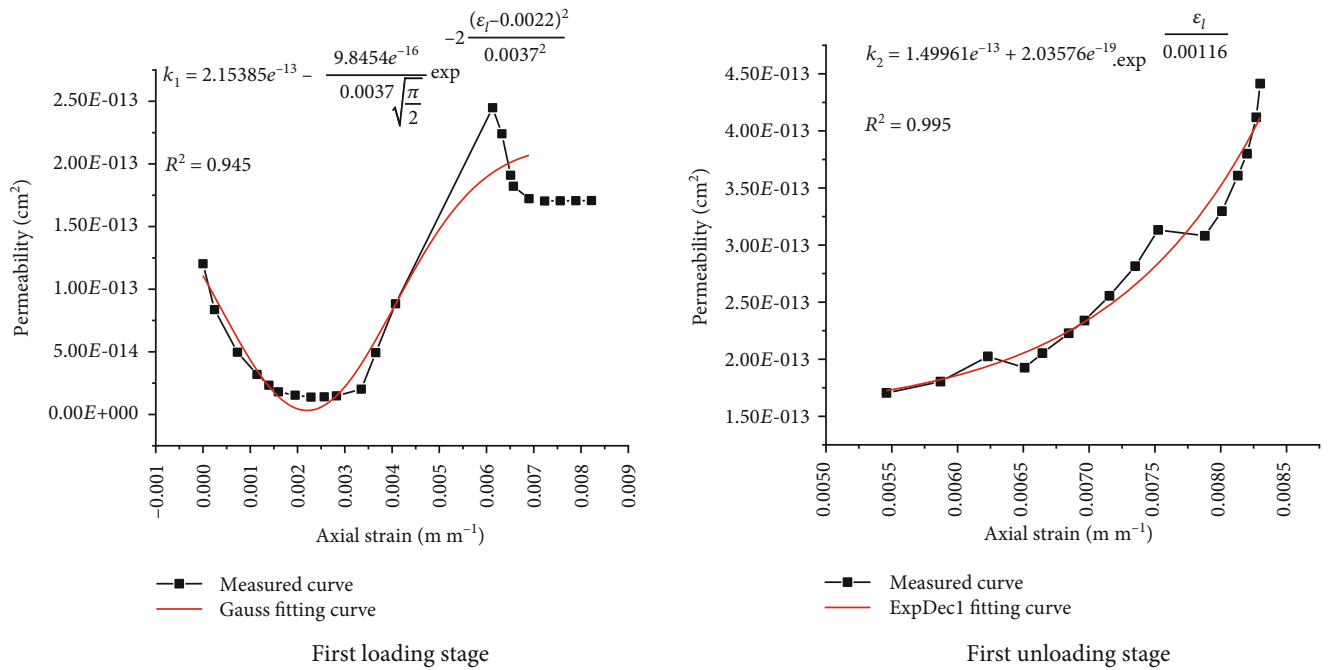

First unloading stage
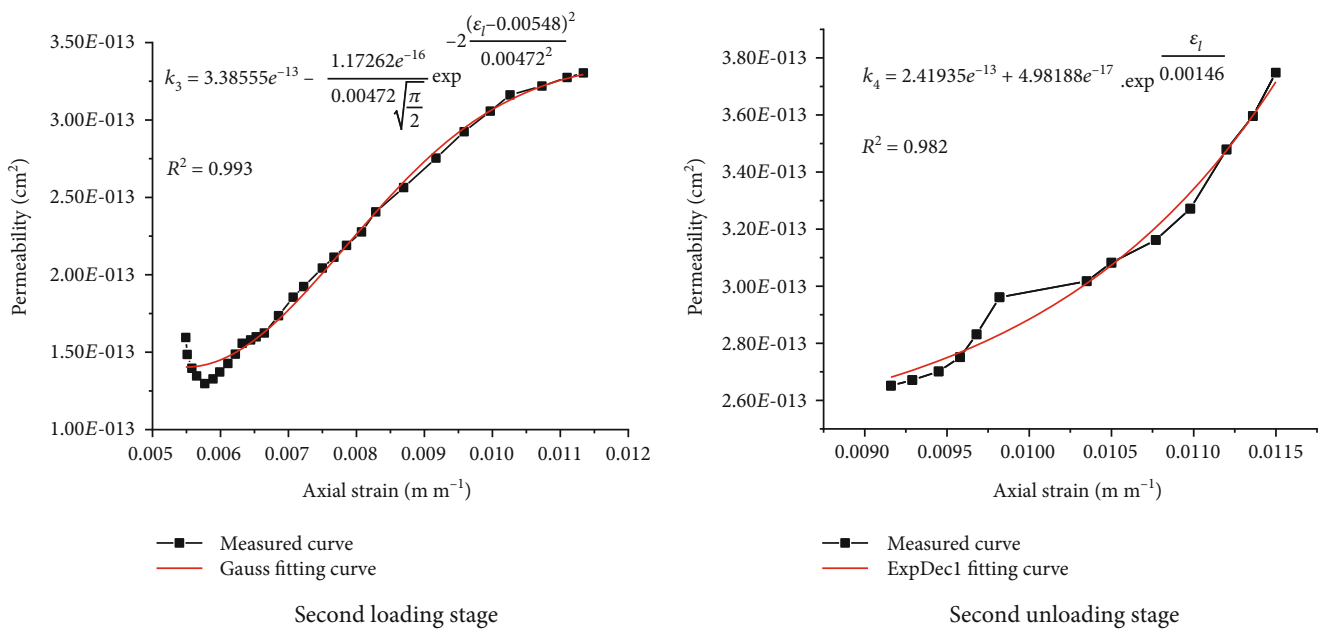

Second unloading stage

(c)

FIGURE 5: Fitting of the relationship between permeability and axial strain of sandstone at different loading and unloading stages.

According to the coal seam parameters revealed via the exploration boreholes in the Yili No. 4 Coal Mine, the quaternary aquifer thickness was about $5 \mathrm{~m}$, the thickness values of the $21-1$ and 23-2 coal seams were $0.94-8.93 \mathrm{~m}$ and $2.6-16.9 \mathrm{~m}$, respectively, and the seam spacing was 4.9-38.8 m. The Yili No. 4 Coal Mine subdivision into coal rock structures is depicted in Figure 2. The first mining face layout and comprehensive column diagram of the upper and lower coal seams are shown in Figure 3.

3.2. Case Verification. Taking the mining in the 21105 and 23213 working faces of the Yili No. 4 Coal Mine as an example, the evaluation method feasibility and rationality of selected parameters were verified. First, the "permeability 


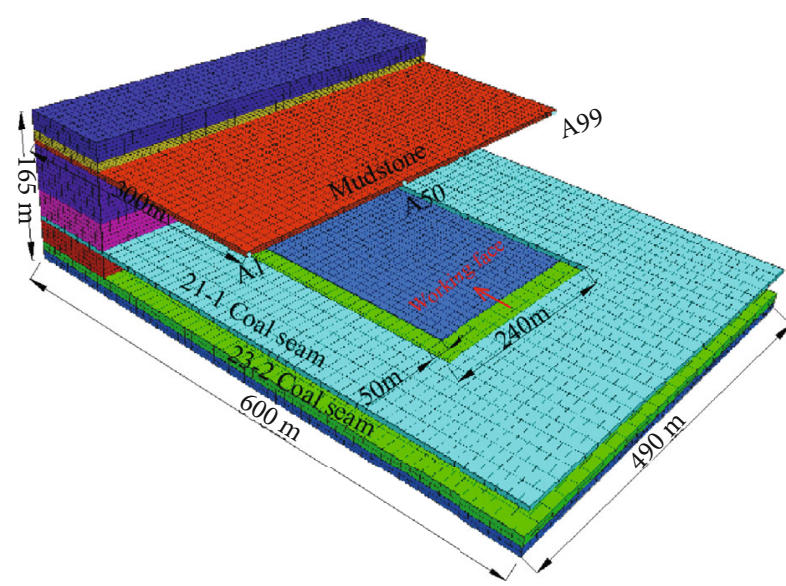

Figure 6: Generalized model and monitoring points' layout.

versus axial strain of mudstone and sandstone under cyclic loading and unloading conditions" curves were constructed through laboratory tests. These curves were subdivided into four stages, and their fitting was performed, as shown in Figures 4 and 5.

Then, the FLAC3D numerical model with dimensions (length $\times$ width $\times$ height $=600 \times 490 \times 165 \mathrm{~m}$ ) was constructed. The upper and lower working face length was $240 \mathrm{~m}$, the staggered distance was $50 \mathrm{~m}$, and the continuous advancing length was $400 \mathrm{~m}$. Monitoring points were set at $5 \mathrm{~m}$ intervals in the aquiclude position in the middle of the advancing direction of the working face, as shown in Figure 6. The model adopted the Mohr-Coulomb criterion, with fixed constraints on the surrounding and lower boundaries. The aquifer maintained a water pressure boundary condition of $0.05 \mathrm{MPa}$, and the physical and mechanical parameters of each rock layer were adopted, as shown in Table 4.

Referring to the multifield coupling model established by Fan et al. [41-43], the loading and unloading stages were specified by the self-developed subprograms written in Fish language and incorporated into the FLAC3D software package. Then, the corresponding permeability-axial strain relationship was selected to simulate the permeability evolution of the overlying rock under the disturbance of shortdistance coal mining. The specific determination process is shown in Figure 7. For the number of loading and unloading times $F=1$, the permeability values of the loading and unloading stages were $k_{1}$ and $k_{2}$, respectively. At $F=2$, the respective values were $k_{3}$ and $k_{4}$. The aquiclude subsidence gradient, the aquiclude horizontal deformation, the seepage rate of overburden, and the permeability variation behavior after mining of the upper and lower coal seams were numerically simulated, as shown in Figure 8.

It can be seen in Figure 8 that after mining of the upper and lower working faces, the maximum values of the subsidence gradient, seepage rate, and horizontal deformation of aquiclude were $0.142 \mathrm{~m} \mathrm{~m}^{-1}, 0.379 \times 10^{-7} \mathrm{~m} \mathrm{~s}^{-1}$, and $0.0075 \mathrm{~m} \mathrm{~m}^{-1}$, respectively. According to the above simulation results, substituting the corresponding membership function and matching it with the corresponding membership degree yielded the Sta evaluation index of 0.8096, corresponding to the stable level of aquiclude.
The water level variation in the observation hole during the mining of the actual working face is shown in Figure 9, with an initial water level of $777 \mathrm{~m}$.

As the working face advanced, the water level continued to drop. When the working face was pushed through the observation hole by $40 \mathrm{~m}$, the water level dropped to the lowest point, reaching $772.2 \mathrm{~m}$. The maximum water level drop was $4.8 \mathrm{~m}$. As the working face continued to advance, the water level began to rise gradually. At $145 \mathrm{~m}$ from the observation hole, the water level finally stabilized at $777.8 \mathrm{~m}$, showing a steady-decreasing-rising-steady variation pattern. After mining, the water level of the working face has not dropped significantly and even increased by $0.8 \mathrm{~m}$ from the initial water level. This implies that mining at the working face did not significantly impact aquiclude, verifying the rationality of the adopted evaluation method.

\section{Variation of the Influence of Aquiclude Stability Factors}

4.1. Test Plan Design. To study the influence of the three factors (namely, the thickness values of the upper and lower coal seams and coal seam spacing) on the groundwater flow field, the coal seam occurrence parameters were generalized based on the comprehensive subdivision of the coal rock structure. The distance between the upper coal seam and the aquifer was kept at $85 \mathrm{~m}$, while other parameters are listed in Table 5 .

To improve the multifactor analysis efficiency and accuracy, the orthogonal method was used to design the experimental plan. The orthogonal array table was designed as $L_{9}\left(3^{4}\right)$, and the specific simulation scheme was adopted, as shown in Table 6.

Model dimensions were as follows: length $\times$ width $=$ $600 \times 440 \mathrm{~m}$, while the model's height was automatically adjusted according to the height and spacing of the coal seams. As the influence of the staggered distance on the experimental results was not considered, zero staggered distances of the upper and lower working faces were assumed. The length of the working face was $240 \mathrm{~m}$, and the continuous advancing length was $400 \mathrm{~m}$. Monitoring points were set with $5 \mathrm{~m}$ intervals in the aquiclude position in the middle of the advancing direction of the working face, as shown in Figure 10. The corresponding mechanical parameters and seepage parameters of rocks were the same as those described in Section 3.

4.2. Numerical Simulation Results. The aquiclude subsidence gradient, horizontal deformation, seepage rate, and permeability variation behaviors in nine adopted schemes were obtained through numerical simulation. Scheme 1 (upper coal seam mining height $3 \mathrm{~m} \times$ lower coal seam mining height $5 \mathrm{~m} \times$ coal seam spacing $10 \mathrm{~m}$ ) was chosen for detailed analysis. The variation behavior of each parameter is shown in Figure 11.

It can be seen in Figure 11(a) that after the double coal seam was mined, the aquiclude tilted and sank to the goaf side. The subsidence gradient varied with horizontal positions, and its positive and negative values corresponded to different tilt and subsidence directions. A positive (negative) value implied that the direction of tilting and sinking coincided with (was opposite to) that of the established 
TABLE 4: Physical and mechanical parameters of the overlying rocks.

\begin{tabular}{|c|c|c|c|c|c|c|}
\hline Lithology & $\begin{array}{l}\text { Density } \\
\left(\mathrm{kg} \mathrm{m}^{-3}\right)\end{array}$ & $\begin{array}{l}\text { Bulk modulus } \\
(\mathrm{GPa})\end{array}$ & $\begin{array}{l}\text { Shear modulus } \\
(\mathrm{GPa})\end{array}$ & $\begin{array}{c}\text { Internal friction angle } \\
\left({ }^{\circ}\right)\end{array}$ & $\begin{array}{c}\text { Cohesion } \\
(\mathrm{MPa})\end{array}$ & $\begin{array}{c}\text { Tensile strength } \\
(\mathrm{MPa})\end{array}$ \\
\hline Silt & 1240 & 0.4 & 0.2 & 13 & 0.1 & 0.08 \\
\hline Gravel & 1240 & 0.6 & 0.3 & 23 & 0.4 & 0.24 \\
\hline Mudstone & 2300 & 1.0 & 0.7 & 20 & 1.1 & 0.62 \\
\hline Sandstone & 2200 & 1.2 & 0.9 & 30 & 0.9 & 0.50 \\
\hline $\begin{array}{l}\text { Sand mud } \\
\text { interbed }\end{array}$ & 2500 & 1.2 & 0.7 & 23 & 0.8 & 0.36 \\
\hline 21-1 coal & 1240 & 1.1 & 0.6 & 20 & 0.3 & 0.32 \\
\hline Mudstone & 2430 & 1.0 & 0.7 & 20 & 0.6 & 0.42 \\
\hline 23-2 coal & 1240 & 1.1 & 0.6 & 20 & 0.3 & 0.32 \\
\hline Sandstone & 2600 & 2.5 & 1.8 & 30 & 1.3 & 1.20 \\
\hline
\end{tabular}

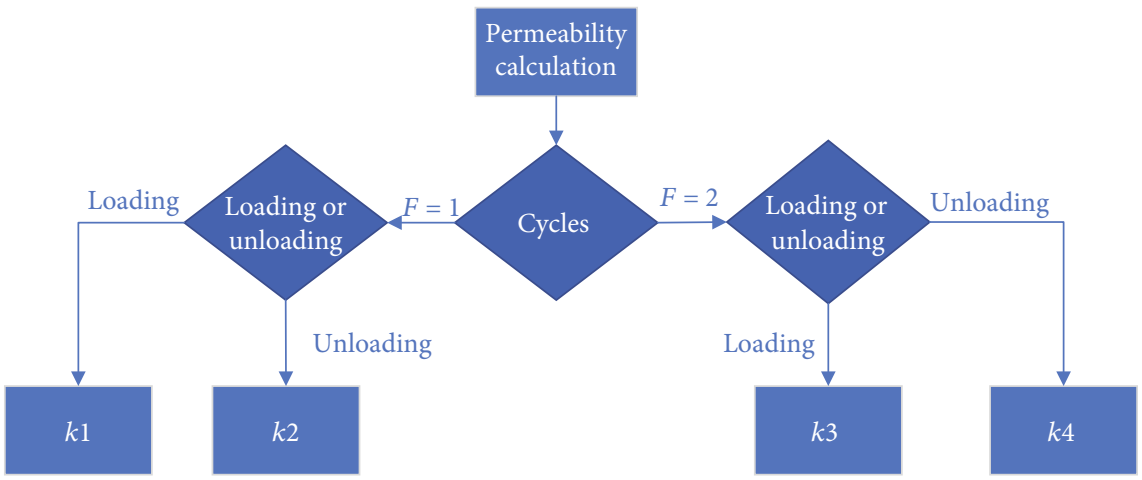

Figure 7: Permeability judgment process.

coordinate axis, respectively. The maximum subsidence gradient was $0.0923 \mathrm{~m} \mathrm{~m}^{-1}$, which was located $30 \mathrm{~m}$ inside the working face end. The subsidence gradient within a certain range in the middle of the working face was zero.

It can be seen from Figure 11(b) that after the double coal seam was mined, the aquiclude horizontal deformation above different working face positions varied and could be split into the following four areas. Area 1 was the original strain area located $70 \mathrm{~m}$ outside the working face end. The aquiclude's horizontal deformation in this area was very small. Area 2 was the tensile deformation area, ranging from $70 \mathrm{~m}$ outside the working face end to $30 \mathrm{~m}$ inside it. In this area, the horizontal deformation value first increased and then decreased, reaching a maximum of 0.0088 at $40 \mathrm{~m}$ outside the working face end. Area 3 was the compression deformation area, ranging from $30 \mathrm{~m}$ inside the working face end to $100 \mathrm{~m}$ inside it. In this area, the horizontal deformation first increased and then decreased, reaching its maximum of $-0.0086 \mathrm{~m} \mathrm{~m}^{-1}$ at $50 \mathrm{~m}$ inside the working face end. Area 4 was located $100 \mathrm{~m}$ from the inside of the working face end to its middle, its horizontal deformation was zero, and thus, it was the deformation recovery area.

According to Figure 11(c), during mining of the double coal seam, the aquifer water seeped in the goaf direction. The arrows at the working face end were denser, which indicates that the seepage rate increased greatly. The highest seep- age rate of $4.02 \times 10^{-7} \mathrm{~m} \mathrm{~s}^{-1}$ was observed at the end of the working face between the upper and lower coal seams. The maximum seepage rate of aquiclude was $0.45 \times 10^{-7} \mathrm{~m} \mathrm{~s}^{-1}$.

Figure 11(d) shows that after the double coal seam mining, the overlying rock permeability exhibited an overall increase. Within a certain range at both ends of the working face, the permeability of the overlying rock increased greatly. For the mudstone layer between double coal seams, the permeability of the lower coal seam increased significantly at the initial stage of mining. In the later stage of mining, due to the compaction effect of the mined-out area and the swelling and plugging of the mudstone after encountering water, the crackinduced permeability began to decrease again. In contrast, near the ends of the working face, the permeability increased due to the presence of open large cracks. For the aquiclude below the aquifer, despite the increasing trend of permeability after the double coal seam mining, the permeability increment was smaller than that in other rock formations.

Figure 12 shows the numerically predicted changes in four aquiclude parameters for nine different schemes. The derived numerical values are listed in Table 7.

A comprehensive analysis of nine sets of test data revealed the following trends.

(1) The maximum subsidence gradient interval of aquiclude was $0.0923-0.1932 \mathrm{~m} \mathrm{~m}^{-1}$. When the upper and 


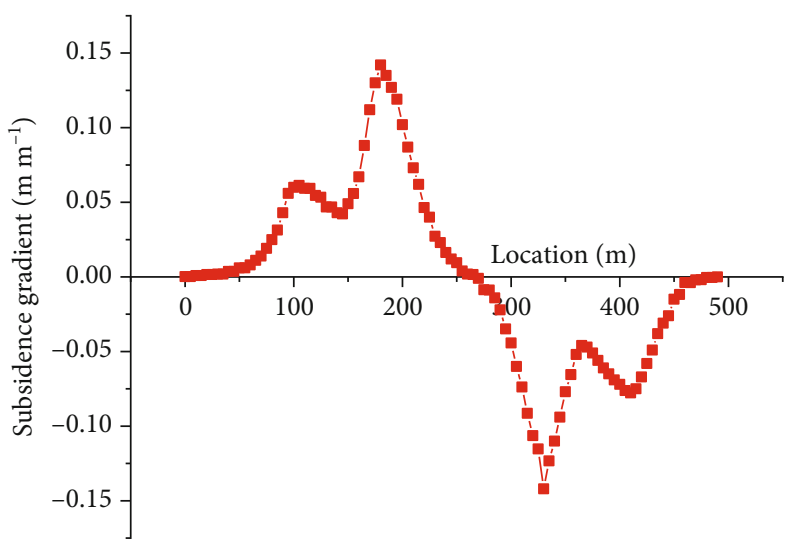

(a) Aquiclude subsidence gradient

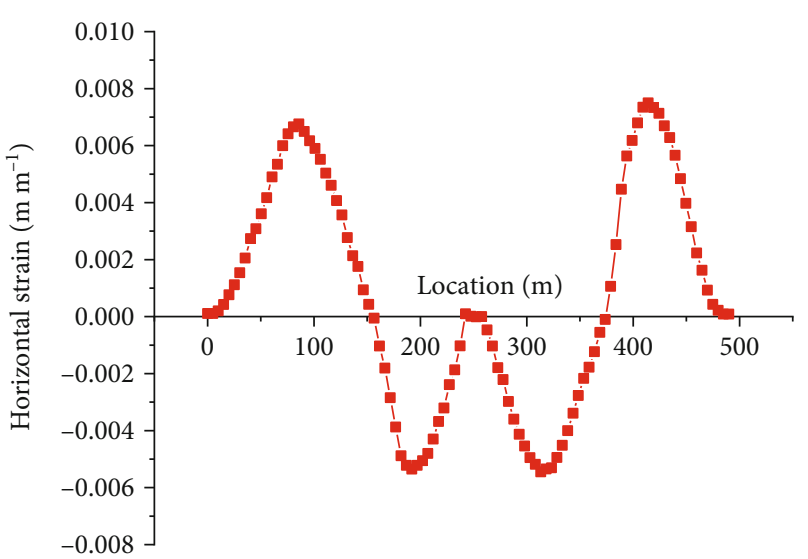

(b) Horizontal deformation of aquiclude

$$
\begin{gathered}
\left(\mathrm{m} \mathrm{s}^{-1}\right) \\
2.7684 E-07 \\
2.7500 E-07 \\
2.5000 E-07 \\
2.2500 E-07 \\
2.0000 E-07 \\
1.7500 E-07 \\
1.5000 E-07 \\
1.2500 E-07 \\
1.0000 E-07 \\
7.5000 E-08 \\
5.0000 E-08 \\
2.5000 E-08 \\
2.0270 E-11
\end{gathered}
$$

(c) Seepage rate of the overburden

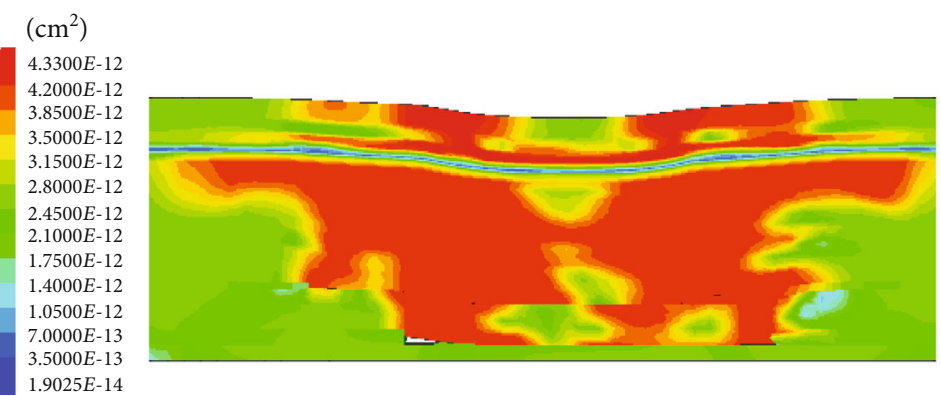

(d) Permeability of overburden

FIGURE 8: Numerical simulation results.

lower coal seams had the smallest mining height ( 3 and $5 \mathrm{~m}$, respectively), the subsidence gradient was the smallest. When the above mining heights were the largest ( 9 and $13 \mathrm{~m}$ ), the subsidence gradient was the maximal. This indicates that the mining height had the greatest impact on the subsidence gradient

(2) The horizontal deformation of the aquiclude in different regions varied and was symmetrical about the middle of the working face as a whole. It could be subdivided into four areas: original deformation area, tensile deformation area, compression deformation area, and deformation recovery area. The maximum horizontal deformation interval of aquiclude was $0.0088-0.0305 \mathrm{~m} \mathrm{~m}^{-1}$. When the upper and lower coal seams had the smallest mining height ( 3 and $5 \mathrm{~m}$, respectively), the horizontal deformation was the smallest. When the mining heights of the upper and lower coal seams were the largest ( 9 and $13 \mathrm{~m}$, respectively), the corresponding horizontal deformation was the largest. This implies that the mining height had the greatest impact on the horizontal deformation

(3) Seepage of aquifer water occurred in the goaf direction. The permeability of the overlying rock generally showed an increasing trend. Especially, the arrows at the end of the working face were denser, indicating rapidly increasing seepage rate. The permeability of the middle area of the goaf increased first and then decreased, while the permeability of the end of the working face continuously increased. The permeability variation trends of nine different schemes were the same; only the degree of change was different. The maximum seepage rate interval 


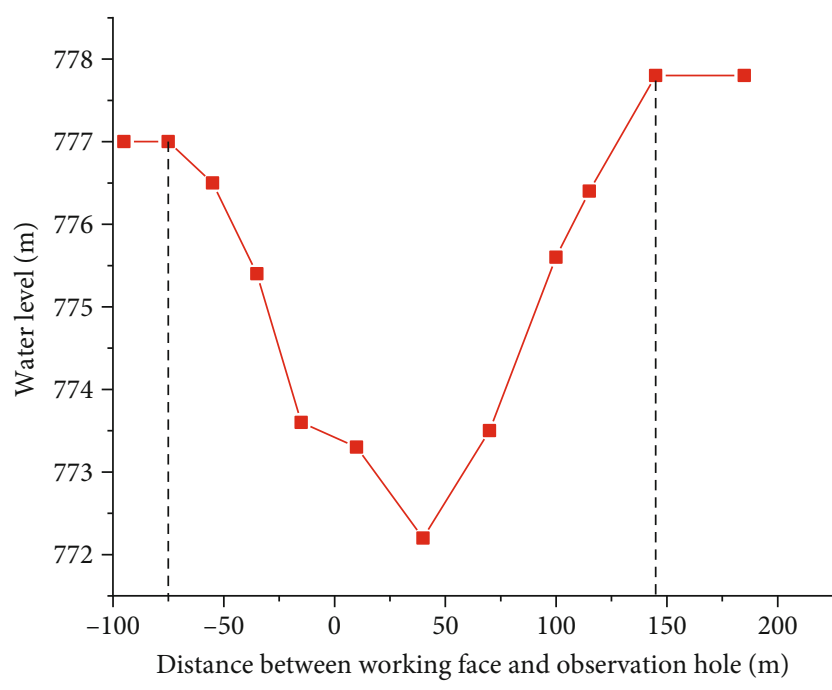

Figure 9: Water level variation in the observation hole.

TABLE 5: Generalization of coal seam occurrence parameters.

\begin{tabular}{lccc}
\hline $\begin{array}{l}\text { Distance between the } \\
\text { upper coal seam and } \\
\text { aquifer }(\mathrm{m})\end{array}$ & $\begin{array}{c}\text { Upper coal } \\
\text { seam mining } \\
\text { height }(\mathrm{m})\end{array}$ & $\begin{array}{c}\text { Lower coal } \\
\text { seam mining } \\
\text { height }(\mathrm{m})\end{array}$ & $\begin{array}{c}\text { Seam } \\
\text { spacing } \\
(\mathrm{m})\end{array}$ \\
\hline \multirow{3}{*}{85} & 3 & 5 & 10 \\
& 6 & 9 & 20 \\
& 9 & 13 & 30 \\
\hline
\end{tabular}

TABLE 6: Simulation scheme design.

\begin{tabular}{lcccc}
\hline Scheme & $\begin{array}{c}\text { Upper coal seam } \\
\text { mining height } \\
(\mathrm{m})\end{array}$ & $\begin{array}{c}\text { Lower coal seam } \\
\text { mining height } \\
(\mathrm{m})\end{array}$ & $\begin{array}{c}\text { Seam } \\
\text { spacing } \\
(\mathrm{m})\end{array}$ & $\begin{array}{c}\text { Empty } \\
\text { column }\end{array}$ \\
\hline 1 & 3 & 5 & 10 & 1 \\
2 & 3 & 9 & 20 & 2 \\
3 & 3 & 13 & 30 & 3 \\
4 & 6 & 5 & 20 & 3 \\
5 & 6 & 9 & 30 & 1 \\
6 & 6 & 13 & 10 & 2 \\
7 & 9 & 5 & 30 & 2 \\
8 & 9 & 9 & 10 & 3 \\
9 & 9 & 13 & 20 & 1 \\
\hline
\end{tabular}

of aquiclude was $0.22-3.62 \times 10^{-7} \mathrm{~m} \mathrm{~s}^{-1}$. The highest seepage rate was attained when the upper and lower coal seams had mining heights of 9 and $13 \mathrm{~m}$, and the spacing was $20 \mathrm{~m}$. The lowest seepage rate was observed when the abovementioned mining heights were 6 and $5 \mathrm{~m}$, and the spacing was $20 \mathrm{~m}$. The effect of seam spacing and mining heights of upper and lower coal seams on seepage rate requires further analysis

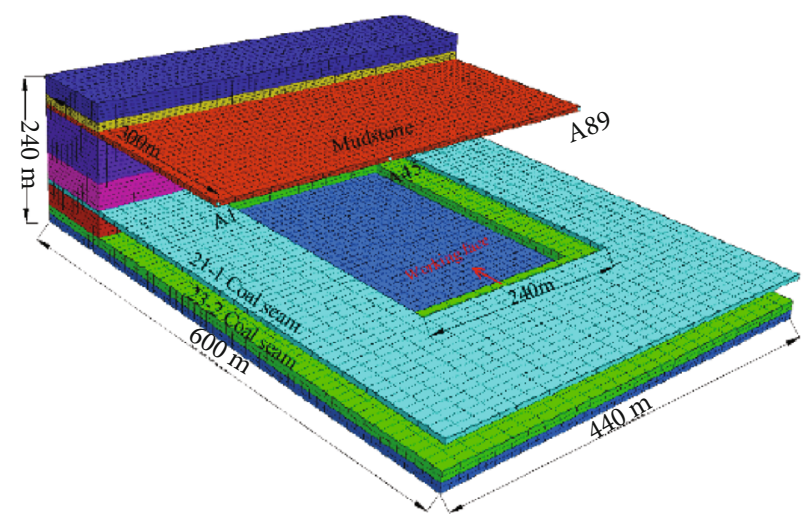

FIGURE 10: Generalized model and monitoring points' layout.

\section{Aquiclude Stability Evaluation and Significance Analysis of Influencing Factors}

5.1. Aquiclude Stability Evaluation. Based on the maximum subsidence gradient, seepage rate, and horizontal deformation parameters of aquiclude of different schemes, the corresponding membership functions were substituted and matched with corresponding parameter weight, yielding the aquiclude stability evaluation indices for nine different schemes adopted in this study. The performed calculation procedure was described below for Scheme 1.

(1) Aquiclude subsidence gradient

$$
\mu(i)= \begin{cases}1, & i<0.1 \\ 2-10 i, & 0.1 \leq i \leq 0.2 \\ 0, & i>0.2\end{cases}
$$

For $i=0.0923 \mathrm{~m} \mathrm{~m}^{-1}, \mu(i)$ was derived as 1 .

(2) Aquiclude seepage rate

$$
\mu(v)= \begin{cases}1, & v<1.0 \times 10^{-8} \\ 1.1-10^{7} v, & 1.1 \times 10^{-7} \geq v \geq 1.0 \times 10^{-8} \\ 0, & v>1.1 \times 10^{-7}\end{cases}
$$

For $v=0.45 \times 10^{-7} \mathrm{~m} \mathrm{~s}^{-1}, \mu(v)$ was calculated as 0.65 .

(3) Aquiclude horizontal deformation

$$
\mu(\varepsilon)= \begin{cases}1, & \varepsilon<0.005 \\ 1.2-40 \varepsilon, & 0.030 \geq \varepsilon \geq 0.005 \\ 0, & \varepsilon>0.030\end{cases}
$$

For $\varepsilon=0.0088 \mathrm{~m} \mathrm{~m}^{-1}, \mu(\varepsilon)$ was assessed as 0.848 . 


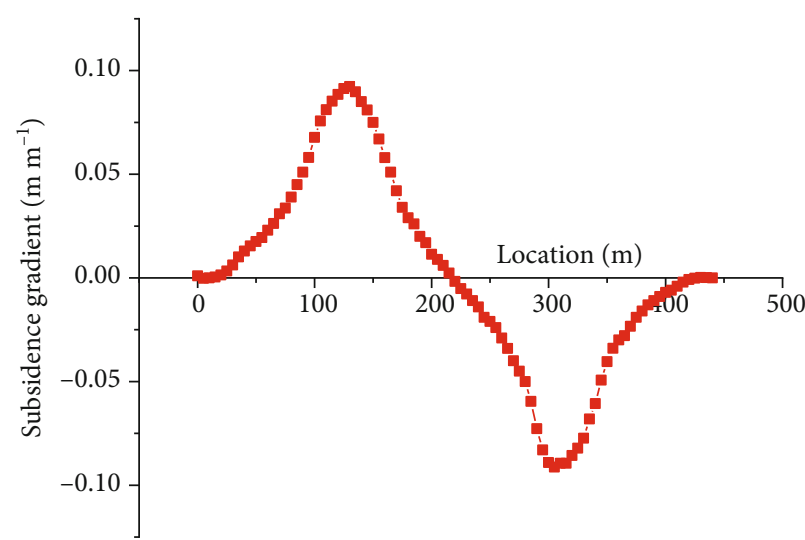

(a) Aquiclude subsidence gradient

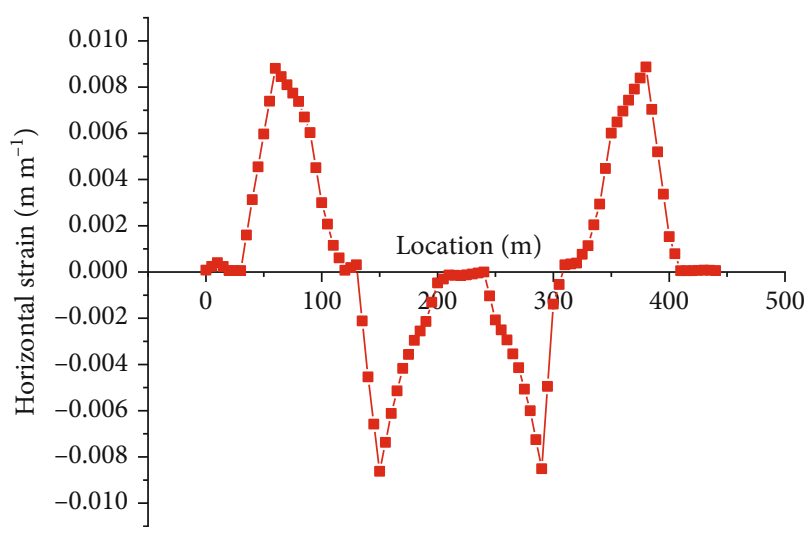

(b) Aquiclude horizontal deformation

$\left(\mathrm{m} \mathrm{s}^{-1}\right)$

4.0246E-07 $4.0000 E-07$ $3.6000 E-07$ $3.2000 E-07$ $2.8000 E-07$ $2.4000 E-07$ $2.0000 E-07$ $1.6000 E-07$ $1.2000 E-07$ $8.0000 E-08$ $4.0000 E-08$

$2.7721 E-11$

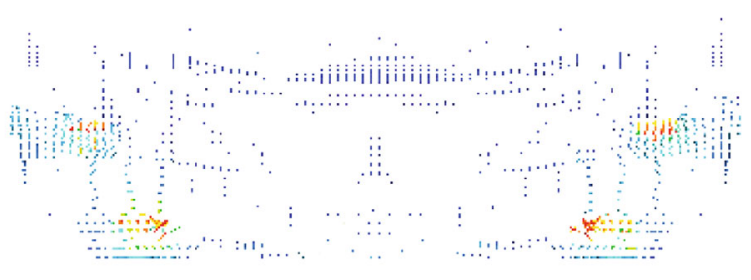

(c) Overburden seepage rate

$\left(\mathrm{cm}^{2}\right)$

4.3300E-12

$4.2000 E-12$

$3.8500 E-12$

$3.5000 E-12$

$3.1500 E-12$

$2.8000 E-12$

$2.4500 E-12$

$2.1000 E-12$

$1.7500 E-12$

$1.4000 E-12$

$1.0500 E-12$

$3.5000 E-13$

$1.8147 E-13$

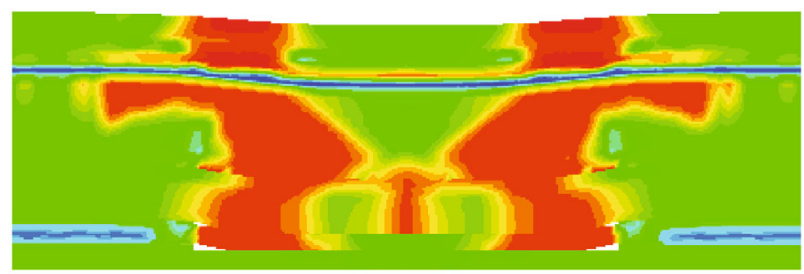

(d) Permeability of overburden

FIgURE 11: Numerical simulation results of Scheme 1.

As a result, the aquiclude stability evaluation index of Scheme 1 was derived as follows:

Sta $=0.1095 \times \mu(i)+0.3090 \times \mu(v)+0.5815 \times \mu(\varepsilon)=0.8033$.

Similarly, aquiclude stability evaluation indices for other eight schemes were obtained, and the respective results are listed in Table 8.

5.2. Significance Analysis of Influencing Factors. Based on the aquiclude stability evaluation indices of the above nine schemes, range and variance analyses were carried out to study the influence of different factors on the aquiclude stability.

(1) Range analysis

The range analysis results are summarized in Table 9.
The range analysis revealed the following decreasing order: $\eta_{\text {Upper coal seam mining height }}>\eta_{\text {Lower coal seam mining height }}>\eta_{\text {Seam spacing }}$. This indicates that the decreasing order of the significance of the influence on the evaluation index of aquiclude stability was as follows: upper coal seam mining height, lower coal seam mining height, and seam spacing. The variation of the evaluation index with the level of each factor is shown in Figure 13, where one can observe that the evaluation index negatively correlated with the height of the upper and lower coal seams and positively correlated with coal seam spacing.

Although the range analysis is simple and easy to implement, it cannot distinguish data fluctuations caused by changes in factor levels from those caused by test errors nor can it give a quantitative estimate of the significance of the influence of factors. To make up for the range analysis deficiencies, the following variance analysis of the experimental results was performed. 


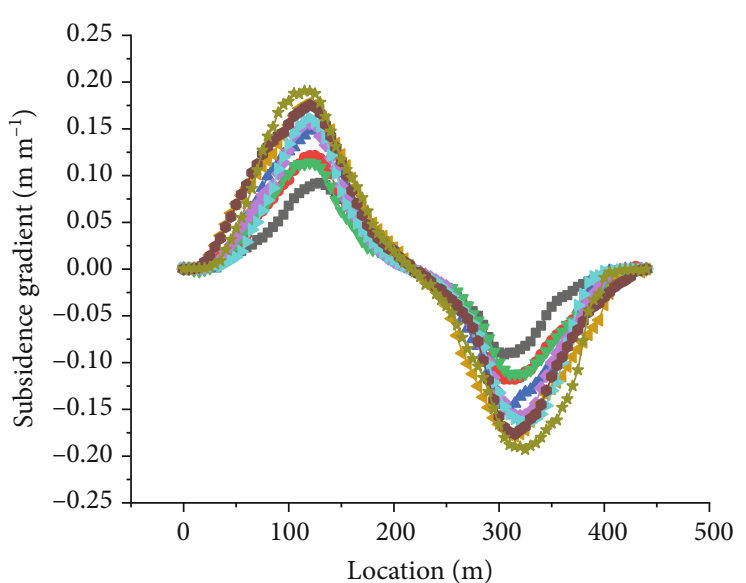

- Scheme 1

$\longrightarrow$ Scheme 2

- Scheme 3

$\rightarrow$ Scheme 4

$\multimap$ Scheme 5

(a) Subsidence gradient

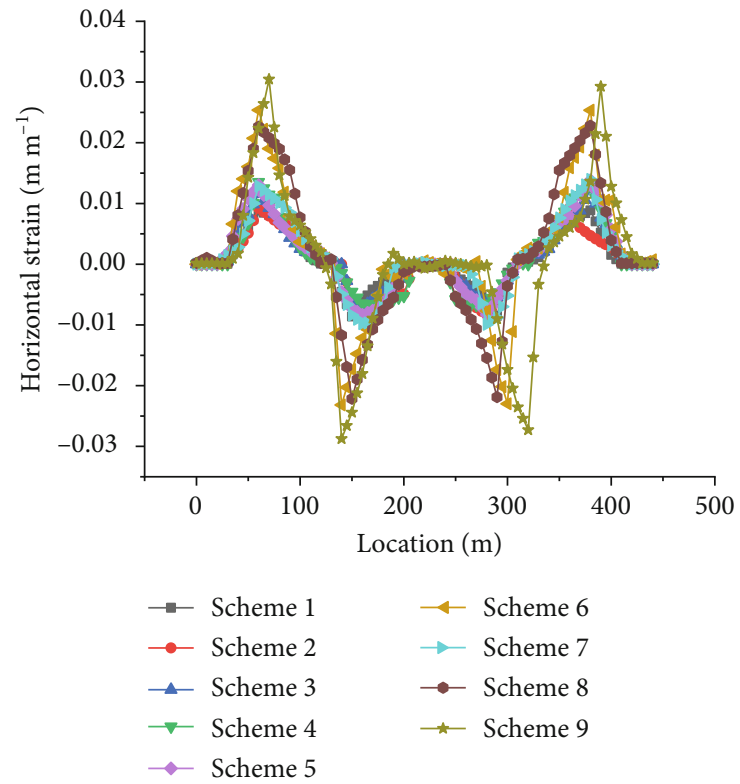

(b) Horizontal deformation

$\left(\mathrm{m} \mathrm{s}^{-1}\right)$

$3.6278 E-07$

$3.5000 E-07$

$3.2500 E-07$

$3.0000 E-07$

$2.7500 E-07$

$2.5000 E-07$

$2.2500 E-07$

$2.0000 E-07$

$1.7500 E-07$

$1.5000 E-07$

$1.2500 E-07$

$1.0000 E-07$

$7.5000 E-08$

$5.0000 E-08$

$2.5000 E-08$

$2.7721 E-11$

$$
\begin{aligned}
& \multimap \text { Scheme } 6 \\
& \rightarrow \text { Scheme } 7 \\
& - \text { Scheme } 8 \\
& \star \text { Scheme } 9
\end{aligned}
$$

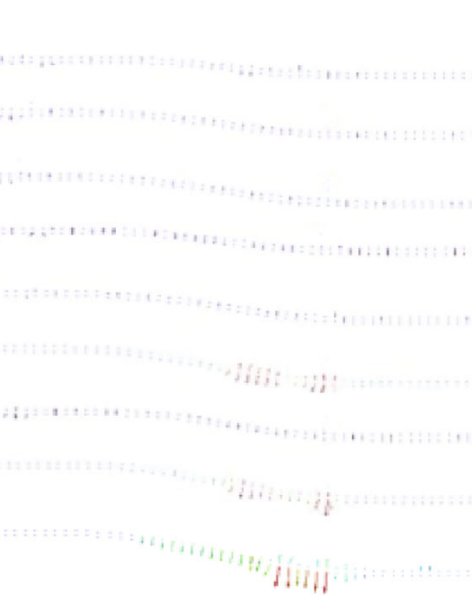

(c) Seepage rate

\begin{tabular}{|l|}
\hline Scheme 1 \\
\hline Scheme 2 \\
\hline Scheme 3 \\
\hline Scheme 4 \\
\hline Scheme 5 \\
\hline Scheme 6 \\
\hline Scheme 7 \\
\hline Scheme 8 \\
\hline Scheme 9 \\
\hline
\end{tabular}

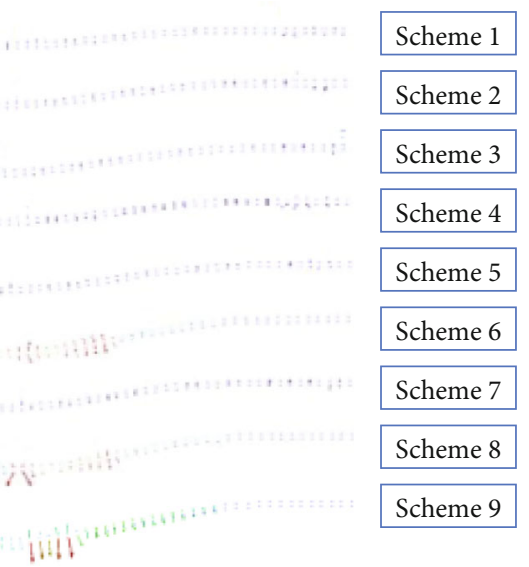

$\left(\mathrm{cm}^{2}\right)$

$4.0315 E-12$

$4.0000 E-12$

$3.7500 E-12$

$3.5000 E-12$

$3.2500 E-12$

$3.0000 E-12$

$2.7500 E-12$

$2.5000 E-12$

$2.2500 E-12$

$2.0000 E-12$

$1.7500 E-12$

$1.5000 E-12$

$1.2500 E-12$

$1.0000 E-12$

$7.5000 E-13$

$5.0000 E-13$

$2.5000 E-13$

$1.8148 E-13$

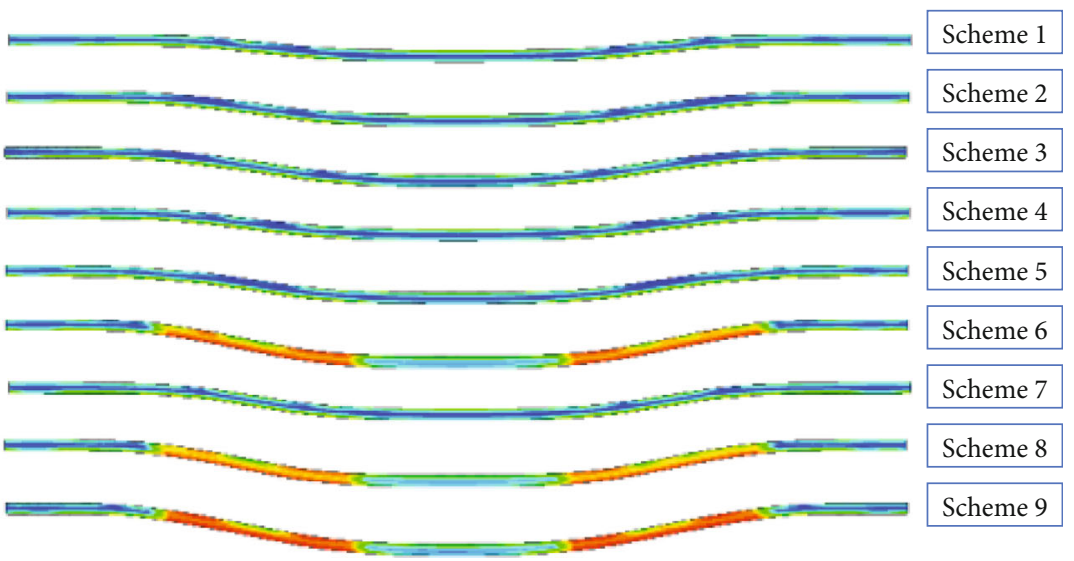

(d) Permeability

FIGURE 12: Numerically predicted changes in aquiclude parameters for nine different schemes. 
TABLE 7: Evaluation factors derived for different schemes.

\begin{tabular}{|c|c|c|c|c|c|c|}
\hline Scheme & $\begin{array}{l}\text { Upper coal seam } \\
\text { mining height }(\mathrm{m})\end{array}$ & $\begin{array}{l}\text { Lower coal seam } \\
\text { mining height }(\mathrm{m})\end{array}$ & $\begin{array}{c}\text { Seam } \\
\text { spacing }(\mathrm{m})\end{array}$ & $\begin{array}{l}\text { Maximum subsidence } \\
\text { gradient }\left(\mathrm{m} \mathrm{m}^{-1}\right)\end{array}$ & $\begin{array}{l}\text { Maximum horizontal } \\
\text { deformation }\left(\mathrm{m} \mathrm{m}^{-1}\right)\end{array}$ & $\begin{array}{l}\text { Maximum seepage } \\
\text { rate }\left(\times 10^{-7} \mathrm{~m} \mathrm{~s}^{-1}\right)\end{array}$ \\
\hline 1 & 3 & 5 & 10 & 0.0923 & 0.0088 & 0.45 \\
\hline 2 & 3 & 9 & 20 & 0.1212 & 0.0092 & 0.46 \\
\hline 3 & 3 & 13 & 30 & 0.1491 & 0.0116 & 0.48 \\
\hline 4 & 6 & 5 & 20 & 0.1139 & 0.0135 & 0.22 \\
\hline 5 & 6 & 9 & 30 & 0.1570 & 0.0138 & 0.45 \\
\hline 6 & 6 & 13 & 10 & 0.1782 & 0.0204 & 3.47 \\
\hline 7 & 9 & 5 & 30 & 0.1640 & 0.0140 & 0.34 \\
\hline 8 & 9 & 9 & 10 & 0.1762 & 0.0227 & 3.2 \\
\hline 9 & 9 & 13 & 20 & 0.1932 & 0.0305 & 3.62 \\
\hline
\end{tabular}

TABle 8: Aquiclude stability evaluation results for nine different schemes.

\begin{tabular}{|c|c|c|c|c|c|c|c|c|c|}
\hline Scheme & 1 & 2 & 3 & 4 & 5 & 6 & 7 & 8 & 9 \\
\hline Index & 0.8033 & 0.7671 & 0.6758 & 0.7493 & 0.6237 & 0.2475 & 0.6475 & 0.1969 & 0.0074 \\
\hline Level & Stable & Stable & Weakly stable & Weakly stable & Weakly stable & Unstable & Weakly stable & Unstable & Unstable \\
\hline
\end{tabular}

TABLE 9: Range analysis.

\begin{tabular}{lcccc}
\hline Scheme & $\begin{array}{c}\text { Upper coal } \\
\text { seam mining } \\
\text { height }(\mathrm{m})\end{array}$ & $\begin{array}{c}\text { Lower coal } \\
\text { seam mining } \\
\text { height }(\mathrm{m})\end{array}$ & $\begin{array}{c}\text { Seam } \\
\text { spacing } \\
(\mathrm{m})\end{array}$ & $\begin{array}{c}\text { Evaluation } \\
\text { index Sta }\end{array}$ \\
\hline 1 & 3 & 5 & 10 & 0.8033 \\
2 & 3 & 9 & 20 & 0.7671 \\
3 & 3 & 13 & 30 & 0.6758 \\
4 & 6 & 5 & 20 & 0.7493 \\
5 & 6 & 9 & 30 & 0.6237 \\
6 & 6 & 13 & 10 & 0.2475 \\
7 & 9 & 5 & 30 & 0.6475 \\
8 & 9 & 13 & 10 & 0.1969 \\
9 & 9 & 2.20005 & 1.24773 & 0.0074 \\
$K_{1}$ & 2.24625 & 1.58775 & 1.52385 & \\
$K_{2}$ & 1.62047 & 0.93081 & 1.94702 & \\
$K_{3}$ & 0.85188 & 0.7334 & 0.4159 & \\
$k_{1}$ & 0.7488 & 0.5292 & 0.5080 & \\
$k_{2}$ & 0.5402 & 0.3103 & 0.6490 & \\
$k_{3}$ & 0.2840 & 0.423 & 0.233 & \\
Range & 0.465 & & & \\
$\eta$ & & & & \\
\hline
\end{tabular}

\section{(2) Variance analysis}

The variance analysis was performed based on numerical simulation results, and the test level $\alpha$ was given. The critical value $F_{\alpha}\left(f_{x}, f_{e}\right)$ was obtained from the $F$ distribution table, where $f_{x}$ and $f_{e}$ were the degrees of freedom (DoF) of the influencing factors and the error, respectively. The calculated $F$ value was compared with the critical value. If $F>F_{\alpha}\left(f_{x}, f_{e}\right)$, this factor had a significant influence on the test results. The greater the difference, the greater the significance of the impact. The results of detailed variance analysis are shown in Table 10. If $F>F_{0.01}\left(f_{x}, f_{e}\right)$, the influence of this factor was considered highly significant and designated by “**" sign in Table 10. If $F_{0.01}\left(f_{x} f_{e}\right)>F$ $>F_{0.05}\left(f_{x}, f_{e}\right)$, the influence of this factor was considered significant and represented by a single “*” sign. If $F<$ $F_{0.01}\left(f_{x}, f_{e}\right)$, the influence of this factor was insignificant.

It can be seen from Table 10 that such factors as upper and lower coal seam mining heights had a significant influence, while the influence of seam spacing was not significant. The decreasing order of significance of each factor's influence on the aquiclude horizontal deformation was as follows: upper coal seam mining height, lower coal seam mining height, and seam spacing. Since this order was identical with the range analysis results, this verified the rationality of the proposed approach.

\section{Discussion}

A single-factor variance analysis was carried out on the evaluation factors of subsidence gradient, horizontal deformation, and seepage rate. The results are summarized in Tables 11-13.

It can be seen from Tables 11-13 that the significant results obtained by the variance analysis of different factors were different. The variance analysis of aquiclude subsidence gradient revealed that the decreasing order of significance was as follows: upper coal seam mining height, lower coal seam mining height, and seam spacing. The variance analysis of aquiclude horizontal deformation derived the following order of significance: upper coal seam mining height $>$ lower coal seam mining height $>$ seam spacing. The variance analysis of aquiclude seepage rate implied the order of significance as follows: lower coal seam mining height $>$ upper coal seam mining height $>$ seam spacing. The main 


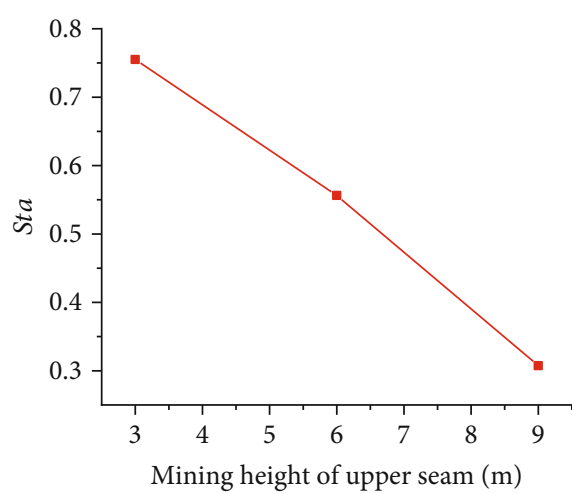

(a) Upper coal seam mining height

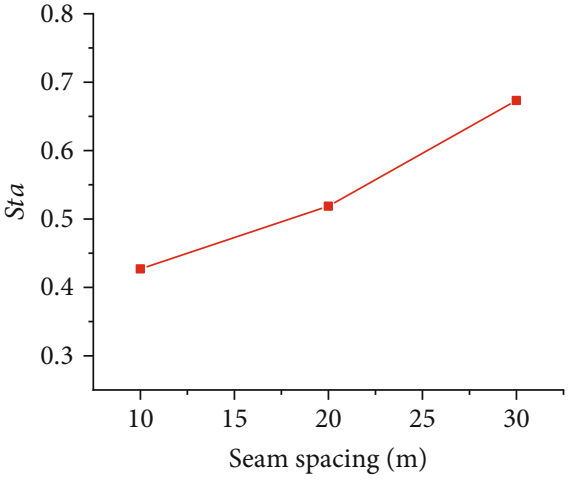

(b) Seam spacing

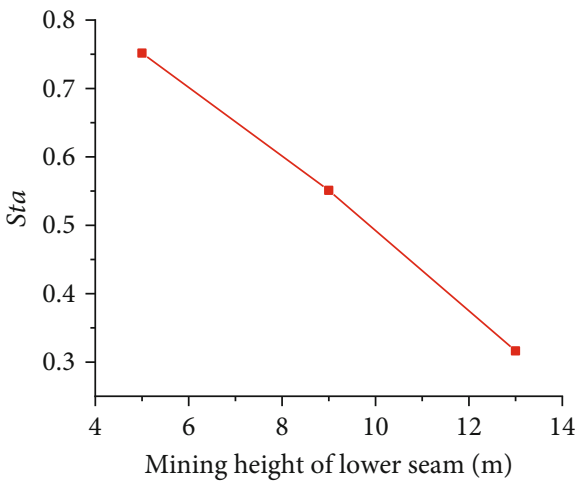

(c) Lower coal seam mining height

Figure 13: The influence trend of various factors.

TABLE 10: Variance analysis.

\begin{tabular}{|c|c|c|c|c|c|c|}
\hline Source of variance & Squared sum of variance & DoF & Squared sum of average variance & $F$ value & Critical value & Significance \\
\hline Upper coal seam mining height & 0.3252 & 2 & 0.1626 & 32.9969 & \multirow{5}{*}{$\begin{array}{l}F_{0.01}(2,2)=99 \\
F_{0.05}(2,2)=19\end{array}$} & \multirow{5}{*}{ * } \\
\hline Lower coal seam mining height & 0.2686 & 2 & 0.1343 & 27.2561 & & \\
\hline Seam spacing & 0.0827 & 2 & 0.0414 & 8.3919 & & \\
\hline Error & 0.0099 & 2 & 0.0049 & & & \\
\hline Sum & 0.6863 & 8 & & & & \\
\hline
\end{tabular}

TABLE 11: Variance analysis of aquiclude subsidence gradient.

\begin{tabular}{|c|c|c|c|c|c|c|}
\hline Source of variance & Squared sum of variance & $\mathrm{DoF}$ & Squared sum of average variance & $F$ value & Critical value & Significance \\
\hline Upper coal seam mining height & 0.0049 & 2 & 0.0024 & 42.3494 & \multirow{5}{*}{$\begin{array}{l}F_{0.01}(2,2)=99 \\
F_{0.05}(2,2)=19\end{array}$} & \multirow{5}{*}{$*$} \\
\hline Lower coal seam mining height & 0.0038 & 2 & 0.0019 & 32.9504 & & \\
\hline Seam spacing & 0.0003 & 2 & 0.0001 & 2.5484 & & \\
\hline Error & 0.0001 & 2 & $5.741 \times 10^{-5}$ & & & \\
\hline Sum & 0.0091 & 8 & & & & \\
\hline
\end{tabular}

reason for such discrepancies is that the stability of the aquiclude is affected by factors such as subsidence, seepage, and deformation. Different factors contribute in controlling the stability of aquicludes, which cannot be assessed by singlefactor analysis. Multiple factors need to be considered simul- taneously. Based on the established aquiclude stability evaluation system and evaluation criteria, a more reliable order of significance was obtained using the comprehensive evaluation index Sta: upper coal seam mining height $>$ lower coal seam mining height $>$ seam spacing. 
TABLE 12: Variance analysis of aquiclude horizontal deformation.

\begin{tabular}{|c|c|c|c|c|c|c|}
\hline Source of variance & Squared sum of variance & DoF & Squared sum of average variance & $F$ value & Critical value & Significance \\
\hline Upper coal seam mining height & $1.95684 \times 10^{-4}$ & 2 & $9.78420 \times 10^{-5}$ & 13.41566 & \multirow{5}{*}{$\begin{array}{l}F_{0.01}(2,2)=99 \\
F_{0.05}(2,2)=19\end{array}$} & \\
\hline Lower coal seam mining height & $1.84311 \times 10^{-4}$ & 2 & $9.21555 \times 10^{-5}$ & 12.63596 & & \\
\hline Seam spacing & $4.14754 \times 10^{-5}$ & 2 & $2.07377 \times 10^{-5}$ & 2.84346 & & \\
\hline Error & $1.45862 \times 10^{-5}$ & 2 & $7.29310 \times 10^{-6}$ & & & \\
\hline Sum & $4.36056 \times 10^{-4}$ & 8 & & & & \\
\hline
\end{tabular}

TABLE 13: Variance analysis of aquiclude seepage rate.

\begin{tabular}{lccccc}
\hline Source of variance & $\begin{array}{c}\text { Squared sum of } \\
\text { variance }\end{array}$ & DoF & $\begin{array}{c}\text { Squared sum of average } \\
\text { variance }\end{array}$ & $F$ value & Critical value \\
\hline $\begin{array}{l}\text { Upper coal seam mining } \\
\text { height }\end{array}$ & $5.55287 \times 10^{-14}$ & 2 & $2.77644 \times 10^{-14}$ & 85.60432 & $*$ \\
$\begin{array}{l}\text { Lower coal seam mining } \\
\text { height }\end{array}$ & $7.17947 \times 10^{-14}$ & 2 & $3.58974 \times 10^{-14}$ & 110.68037 & $F_{0.01}(2,2)=99$ \\
Seam spacing & $5.70620 \times 10^{-14}$ & 2 & $2.85310 \times 10^{-14}$ & 87.96814 & $* *$ \\
Error & $6.48667 \times 10^{-16}$ & 2 & $3.24334 \times 10^{-16}$ & & \\
Sum & $1.85034 \times 10^{-13}$ & 8 & & & \\
\hline
\end{tabular}

\section{Conclusions}

Aquiclude stability is the result of the joint effect of many factors, which may be coupled (interrelated). It is not rigorous to evaluate the stability of the aquiclude from singlefactor analysis. In this paper, a new evaluation method for the stability of aquiclude was proposed, which adopting fuzzy comprehensive evaluation and taking subsidence gradient, seepage rate, and horizontal deformation of the aquiclude as evaluation factors. Then, the stability of weakly cemented aquiclude under different mining disturbance conditions of the close-distance coal seams in the Yili No. 4 Coal Mine was evaluated. Besides, the significance of factors affecting the aquiclude stability under the disturbance of close-distance coal seams mining was analyzed. The following conclusions were reached:

(1) The fuzzy comprehensive evaluation system and standard for the aquiclude stability of the Yili No. 4 Coal Mine were elaborated. The "1-9 scale method" was used to construct the judgment matrix, and the weight factors of aquiclude subsidence gradient, seepage rate, and horizontal deformation were determined to be $0.1095,0.3090$, and 0.5815 , respectively, through normalization and consistency check

(2) The relationship between permeability and axial strain of mudstone and sandstone in different cyclic loading and unloading stages was obtained through laboratory tests. By establishing the FLAC3D model and self-developed code compilation in Fish language, various evaluation factors after mining at 21105 and 23213 working faces were studied, and the comprehensive evaluation index Sta was determined to be 0.8096, which corresponded to the stable level. After the actual coal seam was mined, the water level increased by $0.8 \mathrm{~m}$ compared with the initial value, indicating the stability of the aquiclude and verifying the feasibility of the adopted evaluation system

(3) Based on the comprehensive evaluation index Sta, the range and variance analysis were carried out. It was determined that the aquiclude stability evaluation index of the Yili No. 4 Coal Mine negatively correlated with the mining heights and positively correlated with the seam spacing. The decreasing order of the significance of influencing factors on aquiclude stability was as follows: upper coal seam mining height, lower coal seam mining height, and seam spacing

Based on the above results, it can be seen that the fuzzy comprehensive evaluation method is more practical than a single-factor analysis for aquiclude stability evaluation. This paper studied the influence significance of the mining height of the upper and lower coal seams and seam spacing on the aquiclude stability, which has important guidance meaning for the water conservation mining of close-distance coal seams. However, the influence of working face length, layout, and advancing speed on the aquiclude stability is not considered, and further research is still needed.

\section{Data Availability}

Data from this research are not publicly available. Interested researchers can contact the corresponding author of this article.

\section{Conflicts of Interest}

The authors declare that they have no conflicts of interest. 


\section{Authors' Contributions}

Shuaishuai Liang is responsible for the methodology, software, writing the original draft, and writing the review and editing. Dongsheng Zhang is responsible for the conceptualization and methodology. Gangwei Fan is responsible for the conceptualization and formal analysis. Wenhao Guo is responsible for the data curation. Shouyang Gao is responsible for the software. Shuai Zhang is responsible for the methodology. Zhanglei Fan is responsible for the validation. Wei $\mathrm{Yu}$ is responsible for the data curation.

\section{Acknowledgments}

This research was supported by the National Natural Science Foundation of China (Grant numbers 51974291 and 51774268) and the Postgraduate Research \& Practice Innovation Program of Jiangsu Province of China (Grant number KYCX21_2333).

\section{References}

[1] M. B. Chi, D. S. Zhang, G. W. Fan, W. Zhang, and H. L. Liu, "Prediction of water resource carrying capacity by the analytic hierarchy process-fuzzy discrimination method in a mining area," Ecological Indicators, vol. 96, pp. 647-655, 2019.

[2] P. Ezquerro, C. Guardiola-Albert, G. Herrera, J. A. FernándezMerodo, M. Béjar-Pizarro, and R. Bonì, "Groundwater and subsidence modeling combining geological and multisatellite SAR data over the Alto Guadalentín aquifer (SE Spain)," Geofluids, vol. 2017, 17 pages, 2017.

[3] Q. Ju, Y. Liu, Y. Hu, Y. Wang, Q. Liu, and Z. Wang, "Hydrogeochemical evolution and control mechanism of underground multiaquifer system in coal mine area," Geofluids, vol. 2020, 15 pages, 2020.

[4] J. Guo, J. Liu, Q. Li, and Z. Chen, "Study on the permeability evolution and its formation mechanism of Xiaojihan aquifer coal seam under plastic flow," Geofluids, vol. 2020, 16 pages, 2020.

[5] K. L. Xu, K. Tan, and P. J. Du, “Assessment of the ecological carrying capacity based on high resolution data: a case study of Yuxian, China," in 2016 4th International Workshop on Earth Observation and Remote Sensing Applications (EORSA), p. 2016, Guangzhou, China, July 2016.

[6] D. S. Zhang, G. W. Fan, Y. D. Liu, and L. Q. Ma, "Field trials of aquifer protection in longwall mining of shallow coal seams in China," International Journal of Rock Mechanics and Mining Sciences, vol. 47, pp. 908-914, 2010.

[7] S. Z. Zhang, G. W. Fan, D. S. Zhang, M. W. Chen, and C. G. Zhang, "Study on material properties and similar material proportion of weakly cemented water-resisting strata," Arabian Journal of Geosciences, vol. 12, article 340, 2019.

[8] I. M. Jiskani, Q. Cai, W. Zhou, and S. A. Ali Shah, "Green and climate-smart mining: a framework to analyze open-pit mines for cleaner mineral production," Resources Policy, vol. 71, article 102007, 2021.

[9] G. W. Fan and D. S. Zhang, "Mechanisms of aquifer protection in underground coal mining," Mine Water and the Environment, vol. 34, no. 1, pp. 95-104, 2015.
[10] L. M. Fan, X. D. Ma, Z. Q. Jiang, K. Sun, and R. J. Ji, "Review and thirty years prospect of research on water-preserved coal mining," Coal Science and Technology, vol. 47, pp. 1-30, 2019.

[11] D. S. Zhang, W. P. Li, X. P. Lai, and G. W. Fan, "Development on basic theory of water protection during coal mining in northwest of China," Journal of China Coal Society, vol. 42, pp. 36-43, 2017.

[12] D. S. Zhang, H. L. Liu, G. W. Fan, and X. F. Wang, "Connotation and prospection on scientific mining of large Xinjiang coal base," Journal of Mining \& Safety Engineering, vol. 32, pp. 1-6, 2015.

[13] X. X. Miao, R. H. Chen, and H. B. Bai, "Fundamental concepts and mechanical analysis of water-resisting key strata in waterpreserved mining," Journal of China Coal Society, vol. 32, pp. 561-564, 2007.

[14] X. X. Miao, X. M. Cui, J. A. Wang, and J. L. Xu, "The height of fractured water-conducting zone in undermined rock strata," Engineering Geology, vol. 120, pp. 32-39, 2011.

[15] X. X. Miao, H. Pu, and H. B. Bai, "Principle of water-resisting key strata and its application in water-preserved mining," Journal of China University of Mining \& Technology, vol. 37, pp. 1-4, 2008.

[16] M. G. Qian, X. X. Miao, and J. L. Xu, "Study on the theory of key strata in strata control," Journal of China Coal Society, vol. 21, pp. 2-7, 1996.

[17] L. Wang, X. Miao, Y. Wu, J. Sun, and H. Yang, "Discrimination conditions and process of water-resistant key strata," Mining Science and Technology (China), vol. 20, no. 2, pp. 224-229, 2010.

[18] Q. X. Huang, "Experimental research of overburden movement and subsurface water seeping in shallow seam mining," Journal of University of Science and Technology Beijing, Mineral, Metallurgy, Material, vol. 14, no. 6, pp. 483-489, 2007.

[19] Q. X. Huang and Y. P. He, "Research on overburden movement characteristics of large mining height working face in shallow buried thin bedrock," Energies, vol. 12, no. 21, pp. 4208-4229, 2019.

[20] Q. X. Huang, Y. P. He, and J. Cao, "Experimental investigation on crack development characteristics in shallow coal seam mining in China," Energies, vol. 12, no. 7, pp. 1302-1316, 2019.

[21] L. Q. Ma, D. S. Zhang, and Z. Z. Dong, "Evaluation mechanism and process of aquiclude fissures," Journal of Mining \& Safety Engineering, vol. 28, pp. 340-344, 2011.

[22] J. Sun, L. G. Wang, and G. M. Zhao, "Stability criterion of overburden water-resistant strata supported by filling strip in Shendong special water-preserved mining area," Journal of China University of Mining \& Technology, vol. 47, pp. 957978, 2018.

[23] X. Y. Yu, B. B. Li, R. B. Li, W. S. Duan, and P. L. Liu, “Analysis of mining damage in huge thick collapsible loess of western China," Journal-China University of Mining and TechnologyChinese Edition, vol. 37, pp. 43-47, 2008.

[24] C. J. Booth, "Groundwater as an environmental constraint of longwall coal mining," Environmental Geology, vol. 49, no. 6, pp. 796-803, 2006.

[25] C. J. Booth, E. D. Spande, C. T. Pattee, J. D. Miller, and L. P. Bertsch, "Positive and negative impacts of longwall mine subsidence on a sandstone aquifer," Environmental Geology, vol. 34, no. 2-3, pp. 223-233, 1998.

[26] G. Pessaran, Origin of Mine Water, University of Nottingham, United Kingdom, 1988. 
[27] G. W. Fan, S. Z. Zhang, B. B. Cao, D. S. Zhang, and C. G. Zhang, "Impact of mine panel size on hydraulic permeability of weakly cemented strata," Sustainability, vol. 12, no. 6, pp. 2396-2411, 2020.

[28] H. L. Liu, D. S. Zhang, H. C. Zhao, M. B. Chi, and W. Yu, "Behavior of weakly cemented rock with different moisture contents under various tri-axial loading states," Energies, vol. 12, no. 8, pp. 1563-1576, 2019.

[29] S. Li, G. Fan, D. Zhang et al., "Fracture propagation and hydraulic properties of a coal floor subjected to thick-seam longwalling above a highly confined aquifer," Geofluids, vol. 2021, 12 pages, 2021.

[30] J. Zhang, T. Yang, Y. L. Suo, D. Liu, and F. W. Zhou, "Roof water-inrush disaster forecast based on the model of aquiclude instability," Journal of China Coal Society, vol. 42, pp. 27182724, 2017.

[31] L. Q. Ma, Z. Y. Jin, J. M. Liang, H. Sun, D. S. Zhang, and P. Li, "Simulation of water resource loss in short-distance coal seams disturbed by repeated mining," Environment and Earth Science, vol. 74, no. 7, pp. 5653-5662, 2015.

[32] L. Q. Ma, D. S. Zhang, Z. Y. Jin, S. K. Wang, and Y. H. Yu, "Theories and methods of efficiency water conservation mining in short-distance coal seams," Journal of China Coal Society, vol. 44, pp. 727-738, 2015.

[33] C. L. Zhang, Z. P. Li, and Q. Kang, "Fracture evolution laws of surrounding rock under different strata rock structures in short distance coal seam group," Safety Coal Mining, vol. 49, pp. 91-95, 2018.

[34] C. L. Zhang, J. K. Wu, C. C. Wei, Y. S. Yang, and W. Shen, "Fracture evolution regularity of surrounding rock under different interlaminar strata structure in short-distance coal seams group: a case study in China," Geotechnical and Geological Engineering, vol. 39, no. 4, pp. 3193-3206, 2021.

[35] X. Y. Sun, M. J. Lu, C. Li, and L. T. Miao, “Optimal selection of staggered distance mining in double seams and its influence on water-resisting key strata," Journal of Mining \& Safety Engineering, vol. 38, pp. 51-57, 2021.

[36] Z. Y. Jin, L. Q. Ma, and F. Wang, "Research progress and prospect of aquifuge in shallow coal seam: a case study in the Shendong coal field of China," Electronic Journal of Geotechnical Engineering, vol. 19, pp. 2809-2819, 2014.

[37] Z. Y. Jin, X. Y. Zhao, L. Q. Ma, and M. T. Xu, "Fluid-solid coupling experiment research on water flowing fracture development laws in overburden rocks of shallow buried shortdistance coal seams," Safety Coal Mining, vol. 47, pp. 32-34, 2016.

[38] B. N. Yu, Research on Mining-Induced Water Resisting Property of Clay Aquiclude in Shallow Seam, Xi'an University of Science and Technology, China, 2009.

[39] J. Chen, I. M. Jiskani, C. Jinliang, and H. Yan, "Evaluation and future framework of green mine construction in China based on the DPSIR model," Sustainable Environment Research, vol. 30, no. 1, 2020.

[40] Y. Zhou, W. Zhou, X. Lu et al., "Evaluation index system of green surface mining in China," Mining, Metallurgy \& Exploration, vol. 37, no. 4, pp. 1093-1103, 2020.

[41] Z. L. Fan, G. W. Fan, and D. S. Zhang, "Representation of mining permeability and borehole layout optimization for efficient methane drainage," Energy Reports, vol. 7, pp. 3911-3921, 2021.
[42] Z. L. Fan, G. W. Fan, D. S. Zhang et al., "Optimal injection timing and gas mixture proportion for enhancing coalbed methane recovery," Energy, vol. 222, p. 119880, 2021.

[43] Z. L. Fan, D. S. Zhang, G. W. Fan et al., "Non-Darcy thermalhydraulic-mechanical damage model for enhancing coalbed methane extraction," Journal of Natural Gas Science and Engineering, vol. 93, 2021. 